\title{
Competitiveness Model of Bioethanol Industry
}

\author{
Muzakar Isa and Kusmiati \\ Universitas Muhammadiyah Surakarta \\ Jl. A. Yani Tromol Pos 1 Pabelan Kartasura Surakarta, Jawa Tengah, Indonesia, \\ Phone +62-271-717417 ext 453, E-mail address: muzakarisa@yahoo.com
}

\begin{abstract}
The need for energy is increasing every year. More than $80 \%$ of energy needs met by fossil fuels derived from petroleum and natural gas. To anticipate, the Government issued Presidential Regulation No. 5 of 2006 on the national energy. In this regulation, the government took steps to saving energy and looking for new sources of energy that are renewable and environmentally friendly. One is bioethanol. This study aims to analyze the competitiveness of bioethanol industry in Bekonang Sukoharjo. This study used mixed methods, namely the incorporation of quantitative and qualitative methods in a single study. The measurement of competitiveness is using Porter's Diamond Model. The results show the competitiveness of bioethanol industry is influenced by business strategy, potential buyers, working capital and innovation. Currently, bioethanol industry competitiveness is low.
\end{abstract}

Keywords: competitiveness of smes, bioethanol; alternative energy, business strategy JEL Classification Codes: O17, D1, D24

\section{Model Daya Saing Industri Bioetanol}

\begin{abstract}
Abstrak
Kebutuhan energi meningkat setiap tahunnya. Lebih dari 80 persen kebutuhan energi dipenuhi oleh bahan bakar fosil yang berasal dari minyak bumi dan gas alam. Untuk mengantisipasinya, Pemerintah mengeluarkan Peraturan Presiden Nomor 5 Tahun 2006 tentang energi nasional. Dalam peraturan ini, pemerintah mengambil langkah penghematan energi dan mencari sumber energi baru yang dapat diperbaharui dan ramah lingkungan. Salah satunya adalah bioetanol. Penelitian ini bertujuan menganalisis daya saing industri bioetanol di Bekonang Kabupaten Sukoharjo. Penelitian ini menggunakan mixed method, yaitu penggabungan metode kuantitatif dan kualitatif dalam satu penelitian. Pengukuran daya saing industri menggunakan model Porter's Diamond. Hasil penelitian menunjukkan bawah daya saing industri bioetanol dipengaruhi oleh strategi bisnis, pembeli potensial, modal kerja dan inovasi. Saat ini daya saing industri bioetanol tergolong masih rendah.
\end{abstract}

Kata kunci: daya saing umkm, bioetanol; energi alternatif, strategi bisnis Kode Klasifikasi JEL: O17, D1, D24 


\section{Pendahuluan}

Kebutuhan energi dunia, termasuk Indonesia, terus meningkat setiap tahunnya. Lebih dari $80 \%$ kebutuhan energi tersebut dipenuhi oleh bahan bakar fosil yang berasal dari minyak bumi dan gas alam (Samsuri et al., 2007). Untuk mengantisipasi kebutuhan energi yang terus meningkat, Pemerintah Indonesia mengeluarkan Peraturan Presiden Nomor 5 Tahun 2006 tentang energi nasional. Melalui peraturan ini, pemerintah mengambil langkah penghematan energi dan mencari sumber energi baru yang dapat diperbaharui dan ramah lingkungan.

Kebijakan Pemerintah melalui PP Nomor 5 tahun 2006 tersebut, berdampak pada penghapusan subsidi minyak tanah menyebabkan terjadinya kenaikan harga dari Rp2.500/liter menjadi Rp9.000/liter. Akibatnya, masyarakat sulit mendapatkan minyak tanah dikarenakan harganya yang semakin mahal dan adanya kelangkaan minyak tersebut. Di sisi lain, kebijakan pemerintah tentang energi nasional ini berdampak positif pada industri bioetanol.

Bioetanol merupakan cairan tidak berwarna serta bersifat ramah lingkungan dimana hasil pembakaran berupa gas-gas pencemar udara, seperti Nx dan $\mathrm{CO}$ sangat kecil. Bioetanol tidak menimbulkan efek rumah kaca seperti bahan bakar fosil karena gas berbahaya seperti CO2 berkurang 22\% (Milan 2005). Bioetanol dapat digunakan sebagai pengganti premium/bensin dan kerosin (minyak tanah). Menurut Kusmiyati (2009), pemakaian bioetanol memiliki efisiensi lebih tinggi daripada minyak tanah karena nyala api yang dihasilkan stabil, tidak terlalu besar dan tidak mudah mati. Bioetanol dapat diproduksi dari bahan baku yang mengandung gula, pati ataupun selulosa.

Kabupaten Sukoharjo merupakan salah satu sentra industri Bioetanol di Indonesia. Sentra industri Bioetanol di Kabupaten Sukoharjo, terletak Desa Bekonang dan Desa Sembung di Kecamatan Mojolaban Kabupaten Sukoharjo. Sentra industri ini terdiri dari 70-an pengrajin yang tergabung dalam KUD Sapta Usaha Mulya Kecamatan Mojolaban Kabupaten Sukoharjo. Usaha bioetanol ini merupakan usaha turun temurun yang dilakukan sejak tahun 1940-an, dimana Bioetanol yang dipro- duksi memiliki kadar antara 30\%-90\%. Saat ini mereka mampu memproduksi 1.350 .000 liter per tahun pasar industri Bioetanol Kabupaten Sukoharjo ini adalah perusahan rokok, kimia, tekstil, parfum, farmasi, pengolahan ikan, rumah sakit dan apotik yang berada di Provinsi Jawa Barat, Banten, Jakarta, Jawa Tengah, DIY dan Jawa timur dengan omset per tahun sekitar 10 milyar (KUD Sapta Usaha Mulya, 2012).

Berdasarkan data Disperindag Kab. Sukoharjo Tahun 2012, selama kurun waktu lima tahun terakhir sentra industri Bioetanol Bekonang Sukoharjo mengalami peningkatan jumlah unit usaha, tenaga kerja, investasi, produksi dan nilai produksi. Hal ini berarti sentra industri alkohol tersebut memiliki prospek usaha yang baik, baik bagi pengusaha bioetanol, konsumen maupun bagi Pemerintah Kabupaten Sukoharjo. Hasil produksi bioetanol tersebut sangat menjanjikan sebagai bahan bakar masa depan. Selain sebagai bahan bakar, bioetanol dapat digunakan pula dalam industri kosmetika, industri farmasi dan kesehatan, rumah tangga dan UMKM (sebagai bahan bakar genset), pertanian, laboratorium penelitian, bahan baku fine chemicals lainnya seperti bioeter dan biodietilasetat, dan sebagainya

Industri bioetanol di Bekonang Sukoharjo telah beberapa kali mendapatkan bantuan dari pemerintah daerah, seperti bantuan peralatan, modal, dan lain sebagainya. Dalam menjalankan usahanya, pengrajin bioetanol dihadapkan pada beberapa permasalahan, yaitu persaingan tidak sehat dengan cara saling bersaing dalam menurunkan harga jual produk antarpelaku usaha, proses produksi sangat bergantung pada jumlah permintaan, kurangnya tenaga terampil, tenaga kerja rata-rata berpendidikan rendah dan sulit untuk diajak bekerja sama (mengikuti pelatihan, dan lain-lain), rendahnya modal yang dimiliki pengrajin, dan rendahnya kemampuan pemasaran. Permasalahan tersebut di atas berpengaruh pada rendahnya daya saing industri bioetanol.

Permasalahan lain yang dialami pengrajin Bioetanol adalah mahalnya harga bahan baku (tetes tebu) dan rendahnya mutu bahan baku yang diakibatkan pengusaha kecil dan menengah mengalami kesulitan akses terhadap bahan baku dengan harga dan kualitas terbaik. 
Harga tetes tebu mencapai Rp660.000 per drum dan diprediksi akan semakin tinggi lagi. Untuk mendapatkan tetes tebu sangat sulit, pembelian langsung ke Pabrik Gula harus dalam jumlah besar, minimal 25 ton dalam sekali pembelian, pembelian kepengepul harus melalui pemesanan terlebih dahulu (Suhardi, 2010). Kondisi ini mengakibatkan rendahnya daya saing usaha bioetanol di sentra industri Bioetanol di Bekonang Kabupaten Sukoharjo, sehingga dapat disimpulkan bahwa produk Bioetanol mengalami penurunan daya saing.

Menghadapi permasalahan yang dihadapi pelaku usaha bioetanol di Bekonang Sukoharjo, perlu dilakukan analisis daya saing industri, sehingga dapat diketahui faktor apa saja yang berpengaruh terhadap daya saingnya. Menurut Porter (1980, dan 1990 dalam Robert J. Bennet dan Colin smith, 2002), terdapat empat faktor yang mempengaruhi daya saing suatu industri, yaitu: (1) Faktor kondisi (tingkat pendidikan, modal, inovasi, dan kewirausahaan), (2). Kondisi permintaan (pengembangan produk, struktur industri, segmentasi, dan struktur industri), (3) industri pendukung dan terkait (suplier dan konsumen), dan (4). strategi bisnis, struktur modal dan kinerja perusahaan.

Berdasarkan uraian tersebut, penelitian ini bertujuan menganalisis daya saing industri bioetanol di Bekonang Sukoharjo, serta mengkaji pengembangan usaha Bioetanol melalui diversifikasi bahan baku dan inovasi alat guna meningkatkan daya saingnya.

\section{Metode Penelitian}

Penelitian ini menggunakan mixed method, yaitu penggabungan metode kuantitatif dan kualitatif dalam satu penelitian. Data yang digunakan dalam penelitian ini adalah data primer dan data skunder. Data primer diperoleh dari observasi lapangan dan jawaban responden atas rangkaian pertanyaan yang diajukan oleh peneliti, baik melalui kuesioner maupun indepth interview. Sedangkan data sekunder penelitian ini merupakan data kondisi usaha Bioetanol di Bekonang yang diperoleh dari Dinas Perindustrian dan Pergadangan Kabupaten Sukoharjo dan KUD Sapta Usaha Mulya Kecamatan Mojolaban Kabupaten Sukoharjo.
Dalam penelitian ini terdapat 13 variabel. Adapun Pengukuran variabel tersebut adalah sebagai berikut:

Pertumbuhan perusahanaan: persentase pertumbuhan atas pendapatan pendapatan dibanding tiga tahun sebelumnya,

Tingkat pendidikan: jumlah tahun pendidikan pemilik usaha,

Modal kerja: jumlah modal yang dibutuhkan dalam setiap produksi,

Level Inovasi: pengalaman perusahaan dalam melakukan strategi baru dalam promosi, mencari pembeli baru, suplier baru, distribusi baru yang diiukur dengan skala rating,

Kewirausahaan: tingkat pengambilan risiko UKM dalam pengembangan bisnis yang diukur dengan skala rating,

Pertumbuhan pasar: persentase pertumbuhan penjualan dibandingkan 3 tahun sebelumnya,

Pengembangan produk: tingkat pengembangan produk UKM diukur dengan skala rating,

Potensial pembeli: persentase peningkatan permintaan dalam tiga tahun,

Struktur industri: Posisi relatif UKM dengan pesaing, yang diukur dengan skala rating,

Jumlah pemasok: jumlah pemasok yang terkait langsung dengan UKM,

Kinerja Bisnis: prosentase keuntungan UKM dalam tiga tahun terakhir,

Strategi bisnis: kemampuan menyusun rencana bisnis, yang diukur dengan skala rating, dan Struktur modal: Tingkat truktur modal UKM, yang diukur dengan modal dibagi tingkat bunga.

Populasi dalam penelitian ini adalah pengrajin Bioetanol di Bekonang Kabupaten Sukoharjo yang tergabung dalam KUD Sapta Usaha Mulya Kecamatan Mojolaban Kabupaten Sukoharjo. Total populasi adalah 70 pengrajin. Pemilihan sampel menggunakan metode purposive sampling, yaitu mereka yang telah menjadi pengrajin lebih dari 1 tahun.

Analisis data dilakukan menggunakan metode deskriptif dan metode kuantitatif. Analisis diskriptif bertujuan untuk membuat gambaran mengenai fakta-fakta, sifat-sifat serta hubungan antar fenomena yang diselidiki. Dalam mengukur keunggulan kompetitif digunakan metode Porter's Diamond (1998) karena dengan metode ini akan dapat men- 
jawab hal-hal yang mempengaruhi daya saing. Adapun model persamaan daya saing bioetanol yang digunakan adalah sebagai berikut:

Pertumbuhan Perusahaan $=$

$\alpha+\beta_{1}$ Pendidikan $+\beta_{2}$ Modal Kerja $+\beta_{3}$ Inovasi

$+\beta_{4}$ Kewirausahaan $+\varepsilon$.

Business Performance $=$

$\alpha+\beta_{1}$ Struktur Modal $+\beta_{2}$ Strategi Bisnis $+\varepsilon$.

Pertumbuhan Pasar $=$

a $+\beta_{1}$ Pembeli Potensial $+\beta_{2}$ Pengembangan Produk $+\beta_{3}$ Struktur Industri $+\beta_{4}$ Segmentasi $+\varepsilon$.

\section{Hasil dan Pembahasan}

\section{Profil Pengrajin}

Usaha bioetanol di Bekonang Sukoharjo secara umum merupakan usaha turun temurun, yang memproduksi bioetanol dengan kadar 30\%. Seiring dengan perkembangan teknologi, saat ini terdapat beberapa pengrajin yang mulai memproduksi bioetanol dengan kadar antara $60 \%$ dan $90 \%$. Kapasitas produksi usaha bioetanol berkisar antara 40-100 liter per hari (Koperasi Sapta Usaha Mulya, 2012).

Berdasarkan lamanya usaha sebagaimana Gambar 1, 30\% pengrajin bioetanol telah beroperasi lebih dari 50 tahun, bahkan terdapat beberapa pengrajin telah beroperasi selama 82 tahun. Berdasarkan hasil indepth interview dijelaskan bahwa 30\% pengrajin merupakan pengrajin baru, antara 1 sampai 10 tahun. Mereka secara umum adalah anak atau menantu dari pelaku usaha di Bekonang.

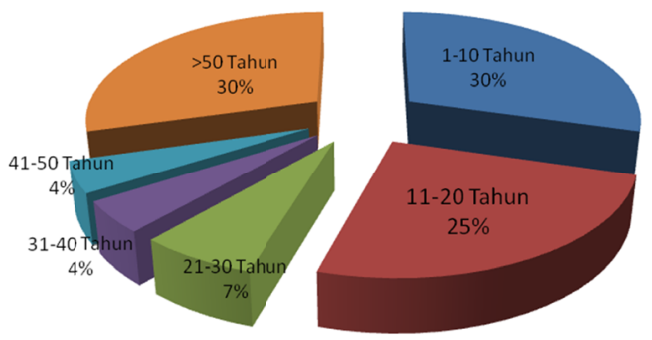

Sumber: data Primer diolah (2012)

\section{Gambar 1. Kategori Umur Usaha Bioetanol di Bekonang Sukoharjo}

Pendidikan Pengrajin Bioetanol di Bekonang masih sangat rendah. Sebesar $41 \%$ responden berpendidikan SD, bahkan terdapat banyak responden yang menempuh pendidikan sampai kelas 3 SD saja, selanjutnya $32 \%$ berpendidikan SMP, 23\% berpendidikan SMA dan 4\% berpendidikan Diploma.

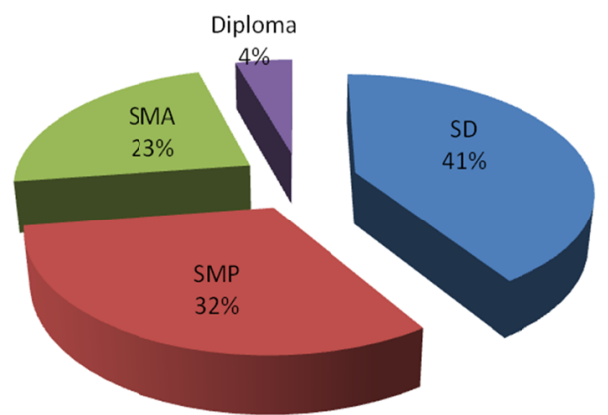

Sumber: data Primer diolah (2012)

Gambar 2. Kategori Tingkat Pendidikan Pelaku Usaha Bioetanol di Bekonang Sukoharjo

Usaha bioetanol di Bekonang sebagian besar belum memiliki legalitas usaha seperti TDUI, TDP, SIUP, NPWP dan merk. Selain belum memiliki legalitas usaha, mereka umumnya termasuk jenis usaha mikro, dimana jumlah tenaga kerjanya secara umum berjumlah 1-5 orang. Berdasarkan gambar 3, dijelaskan bahwa $50 \%$ pengrajin memiliki tenaga kerja sebanyak 1 orang, sebesar $27 \%$ pengrajin memiliki tenaga kerja sebanyak 2 orang, sebesar $14 \%$ pengrajin memiliki tenaga kerja sebanyak 3 orang, sebesar $5 \%$ pengrajin memiliki tenaga kerja sebanyak 4 orang, dan sebesar $2 \%$ pengrajin memiliki tenaga kerja sebanyak 5-6 orang.

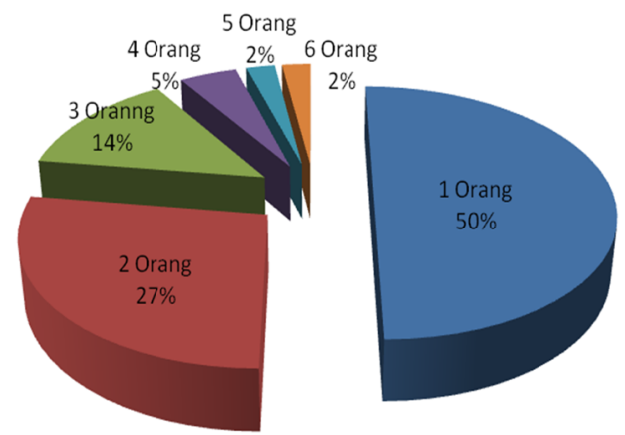

Sumber: data Primer diolah (2012)

\section{Gambar 3. Jumlah Tenaga Kerja di Sentra Usaha Bioetanol Bekonang Sukoharjo}

\section{Daya saing Usaha}

Daya saing industri Bioetanol bekonang Kabupaten Sukoharjo dapat dijelaskan melalui 3 model persamaan. Pertama, kinerja usaha 
dijelaskan oleh struktur modal dan strategi bisnis. Kedua, pertumbuhan pasar dijelaskan oleh pembeli potensial, pengembangan produk, struktur industri dan segmentasi. Ketiga. Pertumbuhan perusahaan dijelaskan oleh tingkat pendidikan, modal kerja, inovasi dan kewirausahaan.

\section{a. Kinerja usaha Bioetanol}

Kinerja Usaha Bioetanol di Sentra Industri Bioetanol Bekonang dapat diestimasi melalui persamaan berikut ini.

$$
\begin{aligned}
& \text { Kinerja Usaha Bioetanol }= \\
& \alpha+\beta_{1} \text { Struktur Modal }+\beta_{2} \text { Strategi Bisnis }+\varepsilon .
\end{aligned}
$$

Tabel 1. Hasil Estimasi Persamaan Kinerja Usaha Bioetanol

\begin{tabular}{lc}
\hline Variabel Independen & Koefisien \\
\hline Strategi Bisnis & $0,722^{*}$ \\
Structur Modal & $0,144^{* * *}$ \\
\hline
\end{tabular}

F statistik $8,140^{*}$

$\mathrm{R}^{2}=0,437$

*** Tidak signifikan pada level $5 \%$

** Significan pada level 5\%

* Significant pada level 1\%

Sumber: Hasil Estimasi Data Primer (2012)

Kinerja usaha Bioetanol di Bekonang Sukoharjo secara positif dan signifikan dipengaruhi oleh strategi bisnis. Strategi bisnis yang dilakukan pengrajin terlihat dari banyaknya pengrajin bioetanol sudah melakukan penilaian atas hasil kerja yang telah dicapai, membuat target yang akan dicapai, dan membuat rencana kerja periode mendatang. Rahayu Puji Suci (2009) menjelaskan bahwa strategi bisnis merupakan kemampuan pengusaha/ perusahaan dalam analisis lingkungan eksternal dan internal perusahaan, perumusan (formulasi) strategi, pelaksanaan (implememtasi) rencanarencana yang dirancang untuk mencapai sasaran-sasaran perusahaan, serta melakukan evaluasi untuk mendapatkan umpan balik dalam merumuskan strategi yang akan datang.

Struktur modal berpengaruh positif tetapi tidak signifikan terhadap kinerja bisnis usaha Bioetanol di Bekonang Sukoharjo. Modal pengrajin secara umum bersumber dari modal sendiri, dan baru $17 \%$ pengrajin yang sebagian sumber modalnya dari lembaga keuangan, baik Bank maupun koperasi. Secara matematis, hubungan kinerja bisnis, struktur modal, dan strategi bisnis adalah sebagai berikut:

b. Pertumbuhan Pasar Usaha Bioetanol di Bekonang Sukoharjo

Pertumbuhan Pasar Usaha Bioetanol di Sentra Industri Bioetanol Bekonang dapat diestimasi melalui persamaan berikut ini.

Pertumbuhan Pasar $=$

$\alpha+\beta_{1}$ Pembeli Potensial $+\beta_{2}$ Pengembangan

Produk $+\beta_{3}$ Struktur Industri $+\beta_{4}$ Segmentasi

Table 2. Hasil Estimasi Persamaan Pertumbuhan Pasar Usaha Bioetanol

\begin{tabular}{lc}
\hline Variabel Independen & Koefisien \\
\hline Pembeli Potential & $0,638^{*}$ \\
Pengembangan Produk & $0,197^{* * *}$ \\
Struktur Industri & $0,041^{* * *}$ \\
Segmentasi pasar & $0,100^{* * *}$ \\
\hline
\end{tabular}

F statistik 27,419*

$\mathrm{R}^{2}=0,763$

*** Tidak signifikan pada level 5\%

** Significan pada level 5\%

* Significant pada level 1\%

Sumber: Hasil Estimasi Data Primer (2012)

Pertumbuhan pasar usaha Bioetanol di Bekonang Sukoharjo positif dan signifikan dipengaruhi oleh pembeli potensial. Pertumbuhan permintaan bioetanol Bekonang terlihat sangat bagus. Apalagi seiring diproduksinya bioetanol dengan kadar di atas 90\%, maka potensialnya semakin meningkat. Hasil ini didukung oleh Ansofino (2012) yang menjelaskan potensial permintaan (pembeli) berpengaruh positif terhadap pertumbuhan pasar.

Aspek pengembangan produk, struktur industri dan segmentasi berpengaruh positif tetapi signifikan atas pertumbuhan pasar bioetanol Bekonang. Pertama, pengembangan produk bioetanol di Bekonang terlihat masih kurang. Selama ini mayoritas pengrajin masih mengandalkan bahan baku tetes tebu dan peralatan yang seadanya. Baru sedikit pengrajin yang mencoba melakukan diversifikasi bahan baku, dan peningkatan teknologi yang digunakan.

Kedua, struktur industri (Posisi relatif 
pengrajin bioetanol dengan pesaing) belum optimal. Peralatan yang digunakan pengrajin bioetanol terlihat masih sederhana. Hal ini berpengaruh pada kualitas bioetanol yang dihasilkan menjadi belum maksimal. Rata-rata bioetanol yang dihasilkan memiliki kadar 30\%, baru sedikit pengrajin yang menghasilkan bioetanol di atas $90 \%$. Belum maksimalnya hasil produksi tersebut akhirnya berpengaruh pada belum optimalnya hasil penjualan dan jumlah konsumen yang terlayani. Dan ketiga, segmentasi atau variasi produk bioetanol belum dikelola dengan baik. Setiap pengrajin bioetanol di Bekonang rata-rata hanya memproduksi 1 jenis produk saja. Mayoritas pengrajin bioetanol memproduksi kadar 30\%. Hal ini berdampak pada masih kecilnya segmentasi konsumen yang terlayani.

\section{c. Pertumbuhan Usaha}

Pertumbuhan usaha bioetanol di Sentra Industri Bioetanol Bekonang dapat dihitung melalui persamaan berikut ini:

Pertumbuhan Perusahaan $=$

$\alpha+\beta_{1}$ Pendidikan $+\beta_{2}$ Modal Kerja $+\beta_{3}$ Inovasi

$+\beta_{4}$ Kewirausahaan

Table 3. Hasil Estimasi Persamaan Pertumbuhan Usaha Bioetanol

\begin{tabular}{|c|c|}
\hline Variabel Independen & Koefisien \\
\hline Pendidikan & $0,271^{* * *}$ \\
\hline Modal kerja & $0,467^{* *}$ \\
\hline Inovasi & $0,280^{* *}$ \\
\hline Risiko Modal (Kewirausahaan) & $0,173^{* * *}$ \\
\hline $\begin{array}{l}\text { F statistik 5,250* } \\
\mathrm{R}^{2}=0,350 \\
* * * \text { Tidak signifikan pada level 5\%, } \\
\text { level } 5 \% \text {, * Significant pada level 5\% } \\
\text { Sumber: Hasil Estimasi Data Primer (2012 }\end{array}$ & Signifi \\
\hline
\end{tabular}

Pertumbuhan usaha Bioetanol di Bekonang Sukoharjo secara positif dan signifikan dipengaruhi oleh inovasi dan modal kerja. Menurut Ginanjar Suendro (2010), inovasi produk yang semakin tinggi akan mempengaruhi kinerja bisninya dan selanjutnya meningkatkan keunggulan bersaing berkelanjutan. Di sisi lain, Nelly dkk (2001) berpendapat bahwa inovasi produk menunjukkan pada pengembangan dan pengenalan produk baru. Inovasi produk dapat berupa perubahan desain, komponen dan arsitektur produk. Drucker (1954, dalam Berthon dkk 1999) menyatakan bahwa inovasi produk merupakan satu hal yang potensial untuk menciptakan pemikiran dan imajiinasi orang yang pada akhirnya menciptakan pelanggan. Menurut Dourgerty (1996) inovasi produk merupakan suatu cara yang penting bagi perusahaan agar tetap dapat beradaptasi dengan pasar, teknologi, serta pesaingan.

Wahyono (2002) mengajukan dua konsepsi inovasi yaitu 1) keinovatifan dan 2) kapasitas untuk berinovasi. Keinovasian adalah fikiran tentang keterbukaan utuk gagasan baru sebagai sebuah kultur perusahaan. Sedangkan kapasitas untuk berinovasi adalah kemampuan perusahaan untuk menggunakan atau menerapkan gagasan, proses, atau produk baru secara berhasil.

Selain aspek inovasi, modal kerja juga berpengaruh positif dan signifikan terhadap pertumbuhan usaha. Modal kerja usaha biotanol, dilihat dari jumlahnya tidak begitu besar. Modal kerja yang ada dipenuhi dari tabungan pribadi dan pinjaman dari lembaga keuangan yang ada di sekitar wilayah Bekonang. Modal kerja sangat penting digunakan untuk membeli bahan baku dan gaji karyawannya. Sebagai catatan, pengrajin bioetanol memiliki bargaining yang rendah terhadap konsumen, yang tercermin dari pola pembayaran konsumen yang selalu mencicil dalam membayar.

Kewirausahaan dan pendidikan pengusaha berpengaruh positif tetapi tidak signifikan terhadap pertumbuhan usaha bioetanol. Pertama, Kewirausahaan adalah kemampuan kreatif dan inovatif yang dijadikan dasar, kiat dan sumber daya untuk mencari peluang menuju kesuksesan. Beberapa literatur manajemen memberikan tiga landasan dimensi-dimensi dari kecenderungan organisasional untuk proses manajemen kewirausahaan, yakni kemampuan inovasi, kemampuan mengambil risiko, dan sifat proaktif (Weerawardeena, 2003). Kewirausahaan terbukti tidak berpengaruh secara signifikan terhadap kinerja usaha kecil. Besarnya koefesien kewirausahaan adalah sebesar positif akan tetapi tidak signifikan. Hubungan yang bersifat positif menunjukkan bahwa semakin tinggi kewirausahaan maka 
akan berpengaruh positif pula terhadap kinerja usaha atau sebaliknya. Kedua, Pendidikan Pengrajin Bioetanol di Bekonang masih sangat rendah. Sebesar $41 \%$ responden berpendidikan $\mathrm{SD}$, bahkan terdapat banyak responden yang menempuh pendidikan sampai kelas 3 SD saja, selanjutnya $32 \%$ berpendidikan SMP, 23\% berpendidikan SMA dan $4 \%$ berpendidikan Diploma. Isa (2009) menjelaskan bahwa pendidikan pengusaha berpengaruh positif dan tidak signifikan terhadap kinerja usaha kecil.

\section{d. Industri pendukung dan terkait (suplier dan konsumen)}

Usaha bioetanol memiliki daya saing yang masih rendah. Hal ini terlihat dari posisi suplier bahan baku dan konsumenya. Suplier bahan baku setiap pengrajin jumlahnya sedikit. Ratarata suplier pengrajin hanya dua orang dan pengrajin banyak yang menilai kualitas bahan baku yang ada kurang baik. Hal ini menunjukkan pengrajin Bioetanol tidak memiliki kekuatan yang baik dalam melakukan tawar menawar bahan baku. Selain itu, pengrajin mengalami kesulitan dalam memperoleh bahan baku yang berkualitas dan kesulitan dalam pengawasan kualitas bahan baku tetes tebu karena minimalnya jumlah pemasok bahan baku.

Konsumen bioetanol adalah industri di wilayah Solo dan sekitarnya. Saat ini pola pembelian yang dilakukan konsumen adalah dengan cara membeli produk langsung dari rumah pengrajin. Adapun secara garis besar cara pembayaran konsumen dengan cara kredit atau tempo. Saat ini pengrajin belum melakukan pengembangan pemasaran produk guna meningkatkan usahanya.

Saat ini di sekitar industri Bioetanol di Bekonang sudah ada koperasi yaitu: KUD Sapta Usaha Mulya Kecamatan Mojolaban Kabupaten Sukoharjo. Keberadaan koperasi ini belum optimal dalam membantu pengrajin dalam mengelola usahanya, baik dalam menyediakan bahan baku, pengadaan peralatan, koordinator penyediaan modal, maupun pemasarannya.

\section{Simpulan}

Berdasarkan hasil analisis dan pembahasan sebagaimana di atas disimpulkan sebagai berikut:
Model daya saing pengrajin bioetanol di sentra industri bioetanol Bekonang dapat dijelaskan oleh aspek kinerja usaha, Pertumbuhan pasar dan Pertumbuhan usaha. (1) Kinerja usaha Bioetanol secara positif dan signifikan dipengaruhi oleh strategi bisnis, (2) Pertumbuhan pasar usaha Bioetanol secara positif dan signifikan dipengaruhi oleh pembeli potensial, dan (3) Pertumbuhan usaha Bioetanol secara positif dan signifikan dipengaruhi oleh inovasi dan modal kerja.

Daya saing pengrajin etanol di sentra industri bioetanol Bekonang tergolong rendah. Kekuatan tawar pengrajin terhadap pesaing, konsumen dan suplier sangat lemah. Koperasi yang ada belum berjalan optimal sebagai lembaga induk dalam mengelola industri bioetanol di Bekonang.

Kadar produk bioetanol di Bekonang secara umum masih $30 \%$. Dengan ini, pengembangan produk dengan meningkatkan kadar bioetranol masih terbuka lebar.

Bahan baku bioetanol terpaku pada tetes tebu, dimana saat ini mulai langka dan harganya yang tinggi. Maka diversifikasi bahan baku sangat layak untuk dilakukan di usaha ini, antara lain dengan bahan baku umbi ilesiles.

Berdasarkan simpulan sebagaimana di atas, diajukan beberapa rekomendasi sebagai berikut:

Perlu adanya difersifikasi bahan baku. Umbi iles-iles merupakan salah satu alternatif terbaik untuk diversifikasi bahan baku tetes tebu. Selain tidak mengganggu ketersediaan bahan pangan nasional, iles-iles merupakan umbi yang ketersediaannya cukup melimpah dan belum dimanfaatkan secara maksimal sehingga tidak mempunyai nilai ekonomi tinggi. Iles-iles merupakan tanaman yang mengandung karbohidrat cukup tinggi yaitu 70-85\% (Kusmiyati, 2009), diketahui juga mengandung glukomanan tertinggi di antara jenis Amorphophallus lainnya di Indonesia (Sumarwoto, 2005). Menurut Imelda dkk (2007) menjelaskan tanaman iles-iles mudah dikembangbiakan baik secara generatif menggunakan biji, ataupun vegetatif menggunakan umbi, bulbil dan setek daun. Sedangkan untuk potensi di Jawa Tengah cukup melimpah 
dilihat dari luas lahan kehutanan yang dipakai mencapai 640.000 hektar (Dinas Pertanian, 2009), maka jika produksi umbi iles-iles sebesar 30-40 ton/hektar dapat dihasilkan 25,6 juta ton umbi iles-iles. Selama ini umbi iles-iles kurang dimanfaatkan secara maksimal oleh masyarakat. Oleh karena itu akan sangat menguntungkan apabila dapat mengubah umbi iles-iles menjadi suatu produk yang mempunyai nilai guna salah satunya dengan untuk dijadikan bahan baku pembuatan bioetanol.

Perlu adanya pengembangan teknologi (peralatan) dalam meningkatkan kadar alkohol. Untuk mendapatkan bioetanol dengan kadar yang lebih tinggi perlu dilakukan pengembangan teknologi. Salah satu arternatif yang ada adalah menggunakan teknologi membran.

Perlu mengotimalkan peran KUD Sapta Usaha Mulya Kecamatan Mojolaban Kabupaten Sukoharjo guna pengembangan usaha bioetanol di Bekonang. KUD dapat berperan koordinator dan membatu pengrajin (anggotanya) dalam mengatasi kekurangan modal, peralatan, bahan baku dan pemasaran.

\section{Ucapan Terimakasih}

Penulis mengucapkan terimakasih kepada DP2M DIKTI atas bantuan Dana Hibah Penelitian RAPID tahun anggaran 2012. Penulis juga mengucapkan terimakasih kepada saudara Sidik Permono, Agus Wahyudi, dan Andre Veno dari Pusat Studi Penelitian dan Pengembangan Manajemen dan Bisnis (PPMB) Fakultas Ekonomi UMS yang telah membantu dalam pencairan data pada penelitian ini.

\section{Daftar Pustaka}

Ansofino. 2012. Grand Desain Industri Unggulan dalam Rangka Menuju Perubahan Struktural Perekonomian Sumatera Barat, Menara Ilmu Vol. I No.27, Jan 2012.

Dinas Perindustrian dan Perdagangan Kab. Sukoharjo, 2012. Data Sentra UKM Kabupaten Sukoharjo. Disperindag.

Dinas Pertanian. 2009. http://www.deptan. go.id.

Imelda M, Wulansari A, Poerba Y.S. 2008. "Regenerasi Tunas dari Kultur Tangkai
Daun Iles-iles (Amorphophallus muelleri Blume)". Biodiversitas, Vol 9 (3).

Isa, Muzakar. 2003. Studi Komunitas industri Mebel di Serenan Klaten, Dikti:Laporan Penelitian Dosen Muda

Isa, Muzakar, 2009. Analisis Klaster dengan Value Chain Analysis: Studi Kasus pada Klaster Mebel Rotan di Surakarta, Jurnal Manajemen dan Bisnis, Vol. 11, No. 2

KUD Sapta Usaha Mulya Kecamatan Mojolaban Kabupaten Sukoharjo, 2012. Profil Pengrajin Bioetanol di Sentra Industri Bioetanol Bekonang Sukoharjo, KUD Mojolaban

Kusmiyati. 2009, "Pemanfaatan Umbi Iles-Iles Sebagai Bahan Baku Bioetanol untuk Bahan Bakar Alternatif di Pedesaan", Laporan kegiatan fasilitas pelaksanaan Riset Unggulan Daerah. Surakarta: LPPM UMS.

Kusmiyati, Arifin., A., G. 2010. Konversi Umbi Iles-Iles Menjadi Bioetanol dengan Metode Konversi dan SSF (Sakarifikasi dan Fermentasi Secara Serentak). Simposium Nasional Rapi IX 2010.

Kusmiyati, Indah, K. 2011. “Konversi Umbi IlesIles Menjadi Bioetanol dengan Metode Hidrolisis Enzim dan Fermentasi Terpisah Menggunakan Bakteri Zymomonas Mobilis. Seminar Rekayasa Kimia dan Proses 2011.

Li, Tiger dan Roger J. Calantone, 1998, “The Impact of Market Knowledge Competence on New Product advantage: Conceptualization and Empirical Examinatio," Journal of Marketing, Vol. 62. Hal. 13-29.

Milan J. M. 2005, “Bioethanol Production: Status and Prospects". Journal of the Science of food and Agriculture. Vol. 10, 42-56.

Peraturan Presiden Republik Indonesia Nomor 5 Tahun 2006 Tentang Energi Nasional

Porter, M.E. 1998. The Competitive Advantage of Nations. London: Macmilan Press Ltd.

Rahayu Puji Suci. 2009. Peningkatan Kinerja Melalui Orientasi Kewirausahaan, Kemampuan Manajemen, dan Strategi Bisnis 
(Studi pada Industri Kecil Menengah Bordir di Jawa Timur), Jurnal Manajemen dan Kewirausahaan, Vol.11, No. 1, Maret 2009: 46-58.

Robert J. Bennet dan Colin Smith. 2002. Competitive Conditions, Competitive Advantage and the location of SMEs, Jounal of Small Business and Enterprise Development, Vol. 9. Number 1, 2002, pp 73-86.

Samsuri, M, Gozan, Mardias, R, Baiquni, M, Hermansyah, H, Wijanarko, A, Prasetyo, B, Nashikin, M. 2007. "Pemanfaatan Selulosa Bagas Untuk Produksi Etanol Melalui Sakarifikasi dan Fermentasi Serentak dengan Enzim Xylanase". Makara. Vol.11, Pp. 17-24.

Suhardi, 2010. "Harga Tetes Tebu Melambung Tinggi". Solopos 13 Februari 2010. Http: //www.solopos.com/2010/sukoharjo/ha rga-tetes-tebu-melambung-tinggi-14650, diakses pada hari selasa 31 Mei 2011 Pukul 13:30 WIB.

Sumarwoto. 2005. Iles-iles (Amorphophallus muelleri Blume); Deskripsi dan Sifat-sifat Lainnya, Biodiversitas, Vol 6 (3): 185-190 ISSN: 1412-033X.

Tatang Hernas Soerawidjaj, 2011, Peluang, Potensi dan Rintangan Pengembangan Industri Bahan Bakar Nabati di Indonesia. Makalah Kongres Ilmu Pengetahuan Nasional (KIPNAS), 8-10 Nopember 2011, Hotel Bidakara, Jakarta.

Wahyono, 2002. "Orientasi Pasar dan Inovasi: Pengaruhnya terhadap Kinerja Pemasaran" (Studi kasus pada Industri Meubel di Kabupaten Jepara). Jurnal Sains Pemasaran Indonesia, Vol I, No 1 Program Magister Manajemen. Universitas Diponegoro. 